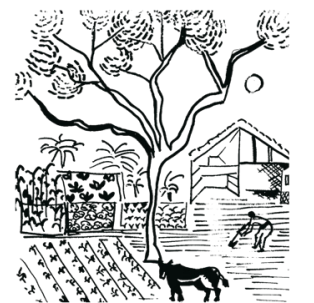

\title{
Reprodução social e agroecologia nos Assentamentos Primeiro do Sul e Nova Conquista Il de Campo do Meio - MG
}

\author{
Ana Rute do Vale \\ Jéssica Danielle Ferreira do Amaral ${ }^{2}$ \\ Leonardo Lencioni Mattos Santos ${ }^{3}$ \\ Paulo Roberto Platini Júnior ${ }^{4}$ \\ Rodrigo Santos de Andrade ${ }^{5}$
}

Resumo: Essa pesquisa pretende mostrar a contribuição do sistema de produção agroecológica para a reprodução social da agricultura familiar, ao possibilitar o escoamento da produção agrícola nos assentamentos Primeiro do Sul e Nova Conquista II, em Campo do Meio-MG. Nesse município, onde a concentração fundiária é uma realidade, a luta dos trabalhadores pela conquista da terra, que ocorre desde a década de 1990, deu origem a esses dois assentamentos e vários acampamentos. Embora estejam encravados no território do agronegócio do café, esses assentados vêm cada vez mais produzindo no sistema agroecológico. Seus produtos - café, cana, leite e seus derivados, hortaliças, frutas, grãos e mel - estão sendo comercializados, principalmente, por meio da Cooperativa dos Camponeses Sul Mineira (Camponesa) em feiras em Campo do Meio-MG e Alfenas-MG. Apesar das dificuldades inerentes à agricultura familiar brasileira, sobretudo para os assentados, a opção pela agroecologia tem mostrado que poderá trazer resultados positivos, embora ainda haja um longo caminho a percorrer.

Palavras-Chave: Assentamentos; Agroecologia; Reprodução social.

\section{Social ReProduction ANd agroecology in the Primero do Sul and Nova ConQuista II settlements in CAMPo do Meio - MG}

ABSTRACT: This research intends to show the contribution of the agroecological production system to the social reproduction of family agriculture, by making it possible to dispose of agricultural production in the settlements of Primeiro do Sul and Nova Conquista II, in Campo do Meio-MG. In this municipality, where land concentration is a reality, the workers' struggle for land conquest since the 1990s has given rise to these two settlements and another several camps. Although they are embedded in the agrobusiness coffee's territory, these settlers are increasingly producing in the agroecological system. Its products - coffee, sugarcane, milk and its derivatives, vegetables, fruits, grains and honey - are mainly sold through the agricultural cooperative Campesinos Sul Mineira (Camponesa) at street market in Campo do Meio-MG and Alfenas-MG. Despite

\footnotetext{
'Professora Associada da Universidade Federal de Alfenas, Graduação, Mestrado e Doutorado em Geografia pela Unesp/ Rio Claro. E-mail: ana.vale@unifal-mg.edu.br

${ }^{2}$ Graduanda em Geografia (licenciatura) pela Universidade Federal de Alfenas. E-mail: jessicaferreiraamaral@gmail.com ${ }^{3}$ Graduando em Geografia (licenciatura) pela Universidade Federal de Alfenas. E-mail: leolencioni@gmail.com ${ }^{4}$ Graduando em Geografia (bacharelado) pela Universidade Federal de Alfenas.E-mail: prplatini@gmail.com ${ }^{5}$ Graduando em Geografia (licenciatura) pela Universidade Federal de Alfenas. E-mail: andrade.rodrigoh@gmail.com
} 
the inherent difficulties of Brazilian family agriculture, especially for the settlers, the option for agroecology has shown to be able to bring positive results, even if there is still a long way to go.

KEYwORDs: Settlements; Agroecology; Social Reproduction.

\section{INTRODUÇÃ̃o}

O modelo de agricultura convencional vem se tornando insustentável, sobretudo para agricultura familiar, que tem grande dificuldade em arcar com os custos da modernização agrícola, e a percepção de que o uso de agrotóxicos compromete cada vez mais a saúde de seus membros e o meio ambiente. Isso sem contar os consumidores de seus produtos agrícolas. Nesse sentido, nas últimas décadas a adoção do sistema agroecológico vem ganhando espaço na agricultura familiar, e em especial nos assentamentos do MST (Movimento dos Trabalhadores Rurais Sem Terra), contribuindo para a reprodução social das famílias assentadas no Primeiro do Sul e no Nova Conquista II.

Os assentamentos Primeiro do Sul e Nova Conquista II estão localizados na mesorregião Sul/Sudoeste do estado de Minas Gerais. Nessa região está situado o território do agronegócio do café, onde predominam pequenas propriedades com exceção do município de Campo do Meio-MG. O município apresenta uma elevada concentração fundiária, representadas por duas grandes propriedades rurais, foco da luta pela reforma agrária na região, e que deram origem aos dois assentamentos.

O primeiro assentamento foi implantado em 1997, na antiga Fazenda Jatobá, e por isso foi denominado de Primeiro do Sul, onde atualmente vivem 42 famílias. A produção convencional de café continua predominante, embora alguns assentados sejam adeptos da agroecologia desde o princípio, e outros estão na fase de transição agroecológica. O segundo foi o Nova Conquista II, em 2014, beneficiando 13 famílias, numa parte das terras da ex-usina de açúcar Ariadnópolis, onde existem 10 acampamentos, com 570 famílias. A monocultura da cana de açúcar foi substituída pela policultura, praticada no modelo agroecológico pela maioria das famílias.

Esses assentados e acampados participam da Cooperativa dos Camponeses Sul Mineiros (Camponesa), fundada em 2012, comercializam café (principal produto), cana de açúcar, leite e seus derivados, hortaliças, frutas, grãos e mel, que também são para o autoconsumo. Além disso, algumas famílias do Primeiro do Sul iniciaram, em 2013, um projeto de transição do cultivo do café convencional para o orgânico, filiando-se à COOPFAM (Cooperativa dos Agricultores Familiares de Poço Fundo e Região) produzindo o "Café Familiar da Terra". Os assentados e acampados do Nova Conquista II também vendem seus produtos agrícolas em duas feiras 
semanais: uma é a Feira Agroecológica e Cultural de Alfenas, em Alfenas-MG, aos sábados; e a outra é a Feira do Produtor, em Campo do Meio-MG, aos domingos.

Essa pesquisa pretende mostrar a contribuição do sistema de produção agroecológica para a reprodução social da agricultura familiar, ao possibilitar o escoamento da produção agrícola nos assentamentos Primeiro do Sul e Nova Conquista II localizados no município de Campo do Meio-MG.

Além do embasamento teórico-conceitual sobre a temática, a pesquisa também se desenvolveu com base em dados secundários do IBGE (Instituto Brasileiro de Geografia e Estatística) e dados primários, com entrevistas realizadas com o presidente e membros da cooperativa Camponesa.

Dessa forma, o trabalho está dividido em três partes. Na primeira, discutese as relações entre agricultura familiar, agroecologia e cooperativismo nos assentamentos. Na segunda, apresenta-se uma caracterização geral da área de estudo. E na terceira mostra-se como a produção agroecológica funciona, como uma estratégia de reprodução familiar nos assentamentos Primeiro do Sul e Nova Conquista II. Os resultados são analisados nas conclusões do presente trabalho.

\section{ASSENTAMENTOS: AGRICULTURA FAMILIAR, AGROECOLOGIA E COOPERATIVISMO}

Embora exista uma infinidade de definições para o conceito de agricultura familiar, de modo geral, há um entendimento de que ela tem, como característica essencial a relação entre propriedade, trabalho e família, na qual a gestão da propriedade e o trabalho são realizados fundamentalmente pelos membros que compõem essa família. A definição de Gasson e Errington (1993, p. 20), citado por Moreira (2008, p. 33) é feita partir de seis características básicas:

A gestão é feita pelos proprietários; os responsáveis pelo empreendimento estão ligados entre si por laços de parentesco; o trabalho é fundamentalmente familiar; o capital pertence à família; o patrimônio e os ativos são objetos de transferência inter geracional no interior da família e; os membros da família vivem na unidade produtiva.

Todavia, há que se destacar que os agricultores familiares não formam um grupo social homogêneo, tendo em vista que sua realidade multiforme é resultante da sua capacidade de adaptação aos diferentes ambientes históricos, e à amplitude das formas que este segmento encontrou e encontra, para se reproduzir em meio às relações capitalistas de produção (LAMARCHE, 1993). Ou, como acredita PLOEG (2014, p. 11), baseado numa metáfora do argentino Raúl Paz, a agricultura familiar é "uma instituição que pode seguir produzindo em um ambiente capitalista 
adverso, da mesma forma que as bactérias anaeróbicas são capazes de sobreviver em um ambiente sem oxigênio".

O Censo Agropecuário de 2006 baseou-se na definição legal de agricultura familiar, sendo que o Estatuto da Terra e o II PNRA (Plano Nacional de Reforma Agrária) "não estabeleçam uma única modalidade de destinação das terras obtidas para a reforma agrária, sendo nítida a ênfase de ambos a respeito da constituição e consolidação de unidades familiares" (MARQUES; DEL GROSSI; FRANÇA, 2012, p. 47). A utilização do termo agricultura familiar se explica pelo fato de que “em nível nacional, 89\% dos estabelecimentos de beneficiários da reforma agrária eram unidades familiares", nesse referido censo (ibidem, p. 48). De acordo com a Lei no 11.326, de 2006, "que estabelece as diretrizes para a formulação da Política Nacional da Agricultura Familiar e Empreendimentos Familiares Rurais, e que fornece o marco legal da agricultura familiar", que é assim definida:

Art. 3: Para os efeitos desta Lei, considera-se agricultor familiar e empreendedor familiar rural aquele que pratica atividades no meio rural, atendendo, simultaneamente, aos seguintes requisitos:

I - não detenha, a qualquer título, área maior do que 4 (quatro) módulos fiscais;

II - utilize predominantemente mão de obra da própria família nas atividades econômicas do seu estabelecimento ou empreendimento;

III - tenha renda familiar predominantemente originada de atividades econômicas vinculadas ao próprio estabelecimento ou empreendimento;

IV - dirija seu estabelecimento ou empreendimento com sua família.

$\S 1$ o O disposto no inciso I do caput deste artigo não se aplica quando se tratar de condomínio rural ou outras formas coletivas de propriedade, desde que a fração ideal por proprietário não ultrapasse 4 (quatro) módulos fiscais (ibidem, p.47).

Cabe aqui ressaltar que, a partir desses argumentos, utilizou-se a denominação de agricultor familiar para os assentados do Primeiro do Sul e do Nova Conquista II, considerando que possuem uma gleba no assentamento, onde cultivam com sua família, e decidem suas estratégias de sobrevivência.

Ressalta-se a importância social e econômica da agricultura familiar para a sociedade brasileira. Dados do Censo Agropecuário do IBGE (2006) mostram que foram identificados 4.367 .902 estabelecimentos de agricultura familiar, representando $84,4 \%$ número total, embora ocupem apenas $24,3 \%$ da área dos estabelecimentos agropecuários brasileiros. No entanto, mesmo cultivando uma 
área menor, a agricultura familiar é responsável por garantir a segurança alimentar no país, produzindo a maior parte dos produtos da cesta básica consumidos pelos brasileiros (cerca de 70\%). Dentre os principais produtos estão os de origem vegetal (mandioca, feijão, milho café e arroz) e animal (suínos, leite e aves).

Outros dados revelam que a agricultura familiar constitui a base econômica de 90\% dos municípios brasileiros, responde por 35\% do PIB (Produto Interno Bruto) nacional, e absorve $40 \%$ da população economicamente ativa do país. Dessa forma, é possível constatar que os agricultores familiares utilizam os recursos produtivos de forma mais eficiente que os grandes estabelecimentos rurais. Embora tenham acesso a uma menor proporção da terra e do financiamento bancário, produzem e empregam mais que os patronais (MARQUES; DEL GROSSI; FRANÇA, 2009).

Tabela 1 - Principais produtos agropecuários advindos da agricultura familiar no Brasil (2006).

\begin{tabular}{l|c}
\hline \multicolumn{1}{c|}{ Produtos } & Total (\%) \\
\hline Mandioca & $87 \%$ \\
\hline Feijão & $70 \%$ \\
\hline Suínos & $59 \%$ \\
\hline Leite & $58 \%$ \\
\hline Aves & $50 \%$ \\
\hline Milho & $46 \%$ \\
\hline Café & $38 \%$ \\
\hline Arroz & $34 \%$ \\
\hline Bovinos & $30 \%$ \\
\hline Trigo & $21 \%$ \\
\hline
\end{tabular}

Fonte: IBGE (2006), organizado pelas autoras.

Veiga (1996, p. 387) ressalta, no entanto que, ao contrário "dos governos do chamado 'primeiro mundo' que adotaram, desde o início do século XX, políticas agrícolas e fundiárias que favoreceram a progressiva afirmação da agricultura familiar e inibiram o desenvolvimento da agricultura patronal", o Brasil fez o inverso, optando pela "enorme tolerância com a oligarquia fundiária e claro favorecimento da agricultura patronal". Dentre as características básicas que diferenciam agricultura familiar de patronal, propostas por esse autor, destacamse as que mais nos interessam nesse trabalho: enquanto no modelo patronal, há “ênfase em práticas agrícolas padronizáveis". No modelo familiar, a ênfase é na 
"durabilidade dos recursos naturais e na qualidade da vida" (ibidem, p. 396). Isso mostra a preocupação desses agricultores com a questão ambiental, uma vez que a relação com a terra é muito diferente da agricultura patronal, que, no fundo, representa o agronegócio, um conceito que, segundo Welch e Fernandes (2008, p. 165), foi formulado pela primeira vez por Davis e Goldberg (1957) e significa:

[...] um complexo de sistemas que compreende agricultura, indústria, mercado e finanças. No decorrer do tempo, o movimento desses complexos e suas políticas formaram um modelo de desenvolvimento econômico controlado por corporações transnacionais, que trabalham com uma ou mais commodities, e atuam em diversos setores da economia.

Por outro lado, a importância da agricultura familiar, sobretudo para a segurança alimentar no mundo, resultou na declaração de 2014 como o Ano Internacional da Agricultura Familiar (AIAF), pela Assembleia Geral das Nações Unidas (ONU). O objetivo foi destacar o perfil da agricultura familiar e dos pequenos agricultores, focalizando a atenção mundial em seu importante papel na erradicação da fome e pobreza, provisão de segurança alimentar e nutrição, melhora dos meios de subsistência, gestão dos recursos naturais, proteção do meio ambiente, e para o desenvolvimento sustentável (FAO, 2014). A agricultura familiar se destaca no papel de gestão dos recursos naturais, proteção do meio ambiente e o desenvolvimento sustentável.

Dessa forma, é impossível ocultar os efeitos negativos da lógica do processo da apropriação da natureza e expropriação de direitos sociais, em que pesem os poderosos interesses econômicos que se esforçam em sustentar o insustentável. Para Altieri (2006), a agricultura sustentável pode ser analisada por uma nova perspectiva, amparada pela valorização da agricultura tradicional.

Muitos dos novos modelos de agricultura que a humanidade precisará para a transição as formas de agricultura mais ecológicas, biodiversas, sustentáveis e socialmente justas, estarão arraigadas na racionalidade ecológica da agricultura tradicional em pequena escala, que representa exemplos estabelecidos de formas corretas de agricultura local (ibidem, p.92).

Já a agroecologia, segundo o referido autor, pode ser entendida como um paradigma científico emergente, que questiona de forma radical a agricultura industrial, buscando fornecer bases conceituais e metodológicas para o desenvolvimento de agroecossistemas sustentáveis. Ele, assim, estabelece as diferenças entre os dois paradigmas (agroecológico e agroindustrial), a partir de determinadas características (quadro 1). 
Quadro 1 - Diferenças entre os sistemas de cultivo agroecológico e convencional.

\begin{tabular}{|l|l|l|}
\hline Característica & Paradigma Agroecológico & $\begin{array}{l}\text { Paradigma } \\
\text { Agroindustrial }\end{array}$ \\
\hline Manejo do solo & $\begin{array}{l}\text { Visa elevar os teores de } \\
\text { matéria orgânica no solo e } \\
\text { ciclagem de nutrientes. }\end{array}$ & $\begin{array}{l}\text { Exaustão do solo; } \\
\text { adubos solúveis. }\end{array}$ \\
\hline $\begin{array}{l}\text { Relação com o meio } \\
\text { ambiente }\end{array}$ & Simbiose & Dominação \\
\hline Mercado & $\begin{array}{l}\text { Restrito; preferência dos } \\
\text { consumidos esclarecidos. }\end{array}$ & $\begin{array}{l}\text { Amplo e de larga } \\
\text { escala. }\end{array}$ \\
\hline $\begin{array}{l}\text { Dependência de insu- } \\
\text { mos externos }\end{array}$ & $\begin{array}{l}\text { Mínima, com aproveitamen- } \\
\text { to dos recursos locais. }\end{array}$ & $\begin{array}{l}\text { Total; adquiridos no } \\
\text { mercado. }\end{array}$ \\
\hline Culturas implantadas & $\begin{array}{l}\text { Diversificação, variedades } \\
\text { tradicionais, e rotação de } \\
\text { culturas. }\end{array}$ & $\begin{array}{l}\text { Monocultivos gene- } \\
\text { ticamente modifica- } \\
\text { dos (transgênicos). }\end{array}$ \\
\hline Participação & $\begin{array}{l}\text { Alta: induz ao envolvimento } \\
\text { da comunidade e formas lo- } \\
\text { cais de organização. }\end{array}$ & $\begin{array}{l}\text { Baixo: decisões de } \\
\text { cima para baixo. }\end{array}$ \\
\hline
\end{tabular}

Fonte: Altieri (2012), adaptado por Dourado (2016, p. 29).

Diante dessa realidade, Altieri (1998) acredita que as características da agricultura familiar podem perfeitamente ser associadas aos princípios da agroecologia, embora a especificidade na sua aplicação seja um dos obstáculos para iniciativas de sua implementação, conforme afirma o mesmo autor em outro trabalho.

Ao contrário dos sistemas convencionais, que apresentam pacotes tecnológicos homogêneos projetados para facilitar sua adoção e conduzir à simplificação dos agroecossistemas, os sistemas agroecológicos exigem que os princípios sejam aplicados de forma criativa, segundo as características de cada agroecossistema particular (ALTIERI, 2012, p. 148). 
Para Ehlers (2006) a agroecologia, cada vez mais, se afirma como um campo de conhecimento multidisciplinar, possibilitando desenvolver, avaliar, analisar e desenhar agroecossistemas por meio de uma série de princípios, conceitos e metodologias. Por conta disso, o autor considera que a adoção da agroecologia nas unidades produtivas de base familiar representa uma estratégia metodológica para encarar a crise, buscando aumentar a produção e a eficiência na utilização dos recursos naturais.

Nesse sentido, a agroecologia já se faz presente em muitos assentamentos pelo Brasil afora, sobretudo naqueles coordenados pelo MST, uma vez que seus "princípios veem ao encontro da busca pela modificação das relações sociais na agricultura, de dependência, exploração e degradação, por práticas que se direcionem para uma agricultura mais sustentável". Isso mostra que a sustentabilidade está incorporada em sua visão sobre reforma agrária, que vai além da conquista da terra. Educação, cooperativas e assistência técnica, são alguns dos aspectos que estão sendo trabalhados nos assentamentos, no que tange os princípios agroecológicos, embora ainda esse processo seja limitado, não atingindo todos os assentados (GOMES; SILVEIRA, 2002).

As famílias assentadas têm o compromisso de promover uma agroecologia cooperada, que crie a base material e técnico-científico para repensarmos as nossas relações com a natureza e com os demais seres humanos, e que eleve a produtividade física dos solos e a produtividade do trabalho, negando a lógica técnico-científico do capital, estimulando a diversificação produtiva, modificando nossos hábitos e atitudes frente à natureza, e alterando nossos hábitos de consumo e de alimentação (ESTEVAM, 2010, s/p.).

Inicialmente, a ideia de cooperação agrícola do MST, segundo Shimanski e Souza (2007) aparece nos acampamentos, aonde vai se efetivar as sociabilidades dos acampados, por meio do desenvolvimento de práticas de cooperação no sentido da ajuda mútua, organizando a vida cotidiana, e buscando resolver a situação de carência e ameaças de despejo. Essa teoria de cooperação recebeu apoio de diversos atores sociais, destacando-se:

a presença da Igreja Luterana, e principalmente da Católica, dos assessores ligados aos partidos de esquerda com influências do marxismo-leninismo, e de alguns segmentos do aparelho do Estado, por intermédio dos técnicos que tinham atuação direta nas organizações (ibidem, p. 244).

Os autores julgam que era necessário pensar na viabilização econômica dos 
assentamentos, numa tentativa "de transformá-los em empreendimentos rentáveis, que reafirmassem a exequibilidade agrária aspirada pelo MST" (ibidem, p. 244). As CPAs (Cooperativas de Produção Agrícolas) surgiram na década de 1980, ideologicamente marcadas pela concepção de que a produção nos assentamentos deveria ser em grande escala e com tecnificação, mas, sobretudo, com a "promessa de maior viabilização econômica, e consequente melhora na qualidade de vida dos agricultores" (ibidem, p.246).

O Sistema Cooperativista dos Assentados (SCA) é implementado em 1922, o qual se basearam nas Cooperativas de Produção Agropecuária (CPAs), e nas Cooperativas de Comercialização e Prestação de Serviços (CPS's). É constituída pelo Estado a Central Cooperativa dos Assentados (CCA's), resultando na organização da Confederação das Cooperativas de Reforma Agrária do Brasil (CONCRAB).

A organização cooperativa é entendida como uma forma de organização do trabalho e da produção, cujo objetivo é expressar, enquanto resultados concretos, a sua própria viabilidade socioeconômica, e o processo de gestão político - territorial em pauta. Ou socioeconômica, cuja introspecção voltase para a própria consolidação da sua sustentabilidade político - ideológica (RIBAS, 1998, p. 44).

O referido autor explica que as formas de cooperação agrícola dos assentados durante a fase de consolidação do SCA foram bem diferenciadas, considerando a própria diversidade no espectro sociopolítico e cultural deles. Dentre as formas de cooperação agrícola nos assentamentos vinculados à égide organizativa do MST, destacamos as CPA's, que são o formato de cooperativa implantado nos assentamentos pesquisados nesse trabalho.

Cooperativas de Produção Agropecuária (CPA's): Foram implantas, dentro do processo cumulativo de experiências internas à estrutura sociopolítica do MST, a partir de 1989, e são consideradas pelo Movimento como uma forma superior da organização da produção, o seu estágio mais avançado. O que diferencia a Cooperativa de Produção Agropecuária de um grupo de produção coletivizado, ou de uma associação, é sua personalidade jurídica, porque ao ser registrada como uma empresa cooperativista passa a ser regida pela legislação cooperativa brasileira. A terra permanece sob o controle do coletivo, ficando apenas uma parcela dedicada à subsistência do associado, e o planejamento do processo produtivo é inerente à expressão organizativa da CPA. A organização/divisão do trabalho se dá, internamente, 
por meio dos setores de produção e serviços, como os setores de grão, animal, de máquinas, e o setor administrativo. O planejamento da produção é coletivo e baseado em estudos técnicos, que definem as linhas de produção e a ordem de prioridades a serem implantadas. No tange à moradia, estas são construídas sob a forma de agrovilas. Quanto à estrutura organizacional, a CPA geralmente é gerenciada por um Conselho de Administração ou Deliberativo ou, ainda, Coordenação. Cada CPA define sua instância representativa, composta por um membro de cada setor de produção e serviço. Nessa instância é escolhido um Conselho Diretor ou uma Diretoria Executiva. O órgão máximo deliberativo de poder dentro da estrutura de uma CPA é a Assembleia Geral da Cooperativa (RIBAS, 1998, p. 54-55 apud CONCRAB, 1996).

Além das várias ações desenvolvidas pelo MST, sobretudo a partir do seu IV Congresso Nacional, em 2000, para internalizar a agroecologia nos assentamentos, a Proposta de Reforma Agrária Popular, lançada em 2007, destaca ainda mais essa temática, uma vez que "norteia a construção de um novo modelo agrícola para o campo brasileiro, indo além de um processo de democratização da terra, e propondo como estratégia o estabelecimento de um sistema agrícola em contraposição ao agronegócio". Nesse sentido, propõe que a produção agrícola nos assentamentos esteja baseada "em uma matriz de produção agroecológica, para a produção de alimentos saudáveis, e respeito à biodiversidade, sem o uso de agrotóxicos, voltado à agroindustrialização do campo e o desenvolvimento do País" (ENGELMANN, 2016). É exatamente nesse sentido que caminham os assentamentos que serão apresentados nesse trabalho.

\section{Caracterização da Área de estudo}

Amesorregião Sul/Sudoeste de Minas configura-se como o território do agronegócio do café, embora não se caracterize pelo predomínio das grandes propriedades, do latifúndio, mas pelas pequenas propriedades. Tal configuração se explica pelo fato de que após gerações de plantio de café, as grandes propriedades passaram por um processo de desmembramento, a partir de sua partilha entre os herdeiros. Nesse sentido, diferente do que ocorrido em outras regiões do país, não houve um processo de reconcentração fundiária. Por esses fatores em que não há grandes produtores de café em grandes propriedades (COALIZÃO DO CAFÉ et al., 2004).

No caso do município de Campo do Meio-MG, a situação não é diferente do restante da mesorregião em termos de produção agrícola, sobretudo da predominância da cafeicultura e da cana-de-açúcar e, em menor escala, a produção 
de feijão, milho e arroz, enquanto as demais culturas são destinadas basicamente à subsistência. $\mathrm{O}$ município de Campo do Meio-MG possui um total de 11.476 habitantes, sendo 10.106 residentes na zona urbana (88\%), e 1412 na zona rural (12\%) (IBGE, 2010).

Essa alta taxa de urbanização, no entanto, revela uma diferença com relação os demais municípios da região, ou seja, a elevada concentração fundiária, que é uma das causa do êxodo rural. Tal situação também tornou Campo do Meio palco de conflitos agrários desde a década de 1990, dando origem aos assentamentos Primeiro do Sul e Nova Conquista II (figura 1).

Figura 1 - Localização dos assentamentos Primeiro do Sul e Nova Conquista II no município do Campo do Meio-MG.

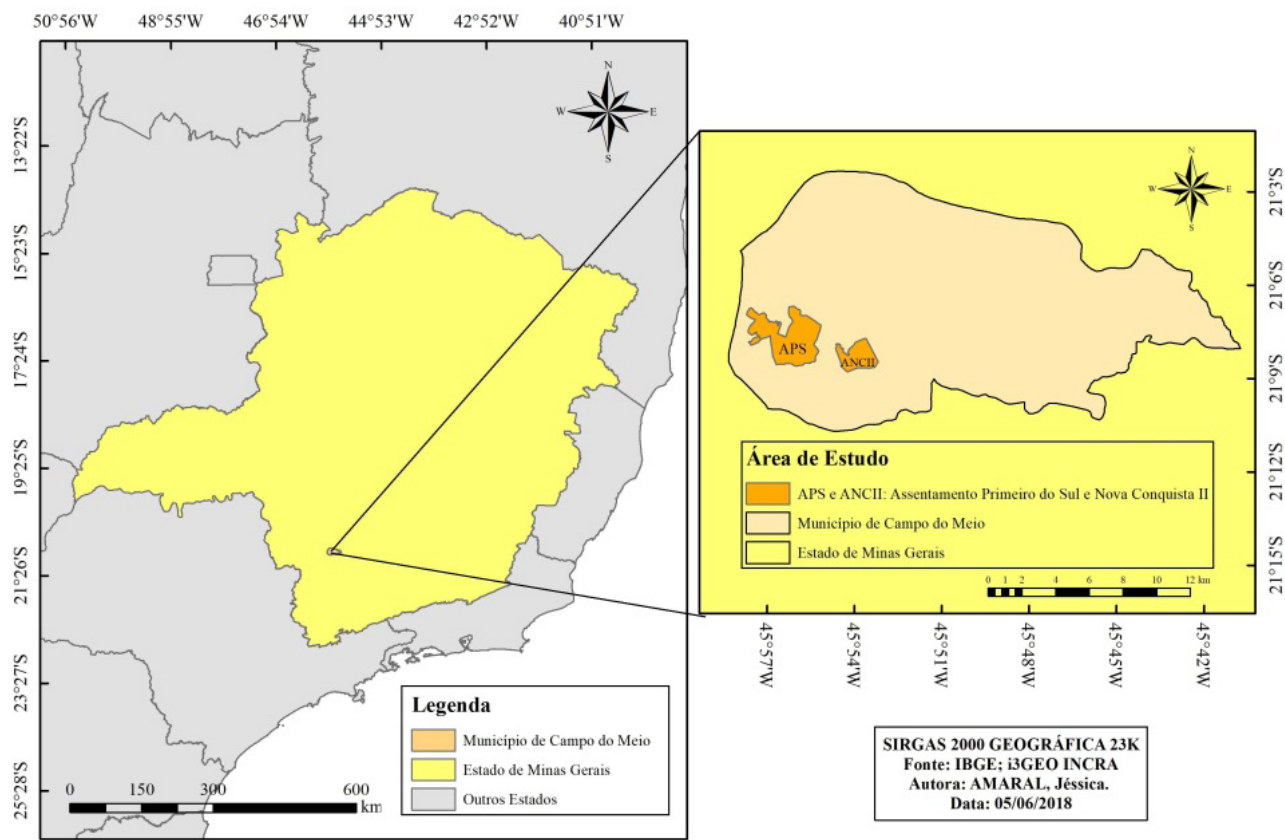

Fonte: IBGE; i3GEO INCRA. Elaborado por Jéssica Danielle Ferreira do Amaral (2018).

Em 1996, ocorreu a primeira ocupação de terras na antiga Fazenda Jatobá, por trabalhadores da ex-usina Ariadnópolis. Em entrevista concedida a Lucas e Vale (2014, p.11), um dos assentados que participaram desse processo relatou que

[...] a situação de exploração da mão-de-obra na usina se prorrogou durante os 
anos e teve seu desfecho em 1995, com uma grande greve geral (cerca de 100 dias), articulada pelo Sindicato de Trabalhadores Rurais de Campo do Meio (MG) e região (Alfenas, Coqueiral, Guapé, Ilicínea, Paraguaçu, Santana da Vargem, e Varginha), que entraram em contato com representantes da Central Única dos Trabalhadores (CUT) de Belo Horizonte, que posteriormente contataram representantes do MST da região do Vale do Rio Doce. Nesse momento, os funcionários da usina já não recebiam seus vencimentos há quatro meses, além dos demais direitos trabalhistas. Além disso, a usina entrou em processo pré-falimentar (LUCAS; VALE, 2014, p. 11).

Os autores explicam que no início, esses trabalhadores cogitaram a possibilidade de ocupar uma área da usina como forma de compensar as dívidas trabalhistas, mas mudaram de ideia quando souberam que existia outra fazenda - a Jatobá -, com uma área total 880 hectares, abandonada e falida havia 4 anos, outrora grande produtora de café. Como a propriedade estava em processo de arremate, para quitação de dívidas junto à União, os trabalhadores acreditaram na possibilidade de transformá-la assentamento. E isso acabou ocorrendo em apenas seis meses após a ocupação, por cerca de 50 famílias, após a desapropriação efetuada pela União, mediante pagamento de indenização ao antigo proprietário (LUCAS; VALE, 2014). Esse processo configura-se como a tal reforma agrária de mercado, um tipo de política na qual criam-se assentamentos a partir de latifúndios "comprados" pelo governo. Ou seja, mantém-se a concentração fundiária ao permitir que, com essa indenização, o latifundiário possa comprar outras propriedades. Fernandes (2007, p.159) explica como funciona:

[...] O controle do território e as formas de acesso à terra é objetivo da mercantilização da reforma agrária. Não importa para o capital ser dono da terra; o que importa é que a forma de acesso seja por meio de relações de mercado, de compra e venda. O controle da posse da terra é um dos trunfos do agronegócio. É fundamental que a terra seja disponível para servir à lógica rentista.

A partir daí, a antiga Fazenda Jatobá transformou-se no assentamento Primeiro do Sul, que recebeu essa denominação por ter sido o primeiro a ser criado no sul de Minas. No início, as famílias assentadas não eram somente de Campo do Meio, mas também de outros municípios do Sul de Minas (Santana da Vargem, São Sebastião do Paraíso, Campos Gerais etc.), bem como do Norte de Minas (Porteirinha) e Vale do Jequitinhonha (Minas Novas e Novo Cruzeiro). Esses últimos eram trabalhadores volantes que atuavam principalmente na colheita de 
café na região. Por conta disso, Mota (2008, p. 42) afirma que nesse município “a luta pela reforma agrária nasceu da necessidade das famílias que trabalhavam para os fazendeiros produtores de café da região, dentro de um sistema de exploração, maus tratos e desrespeito" (MOTA, 2008, p.42).

Com a implantação do assentamento, o INCRA (Instituto Nacional de Colonização e Reforma Agrária) o dividiu em 40 lotes, quando cada família recebeu cerca de 15 hectares, tendo optado pelo trabalho individual, mas mantendo os espaços comuns de forma coletiva, bem como os usos da energia elétrica, do terreiro para a secagem do café e do silo, além dos equipamentos: descalçadeira e da moedeira de café, torrador de café e tanque de resfriamento do leite. Como se pode notar, a principal atividade agrícola permaneceu sendo a cafeicultura, embora também cultivem feijão, milho, banana, frutas, e tenham criação de gado leite e de animais de pequeno porte (LUCAS; VALE, 2014). A manutenção da produção de café pode ser explicada pelo fato de que esses assentados se aproveitaram das condições climáticas e edáficas da região, bem como da estrutura de beneficiamento e comercialização existente, mesmo que como já mencionado anteriormente, a ideologia do MST, que coordena o assentamento, recrimine o predomínio da monocultura. Na realidade, os assentados sentem os aspectos negativos dessa opção produtiva.

Inicialmente, as famílias não obtiveram sucesso, pois não foram orientadas tecnicamente sobre a possibilidade de cultivo de outras culturas. Ademais, o fato de o assentamento estar inserido em um contexto econômico mercadológico de uma região tradicionalmente produtora de café, acabou por induzir essas famílias a permanecerem na cafeicultura, principalmente pela expectativa de facilidade no escoamento da produção a bons preços. Com essa expectativa não atingida, a maioria dos assentados ficaram insatisfeitos, conforme os relatos coletados (LUCAS; VALE, 2014, p. 14).

A forma de comercialização dessa produção de café convencional ocorre por meio de cooperativas da região como a COOPERCAM (Cooperativa dos Cafeicultores de Campos Gerais e Campo do Meio) e CAPEBE (Cooperativa Agropecuária de Boa Esperança), as quais financiam boa parte dos insumos e agrotóxicos, ficando seus valores registrados na conta do cooperado, que poderá efetuar o pagamento na safra seguinte, sendo subtraído o valor devido da colheita subsequente. Já em termos de organização interna foi criada a Associação dos Assentados da Fazenda do Primeiro do Sul (ASFAPSUL), que viabiliza as ações das famílias assentadas, facilitando as intermediações burocráticas e buscando a 
captação de recursos junto ao governo, no que tange ao crédito para infraestrutura, plantio, etc (LUCAS; VALE, 2014).

Nesse processo de luta pela terra no Primeiro do Sul, em parte fomentada pelos trabalhadores da ex-usina de cana-de-açúcar Ariadnópolis que lutavam contra o antigo proprietário para conseguirem o pagamento de dívidas trabalhista, surgem as ocupações nos 3.600 hectares dessa fazenda, outrora ocupada apenas pela plantação de cana-de-açúcar.

O titular desse imóvel é a Companhia Agropecuária Irmãos Azevedo (CAPIA), detentora de uma dívida de mais de $\mathrm{R} \$ 300$ milhões em impostos, empréstimos, e causas trabalhistas. Assim, desde 1996, vários acampamentos passaram a compor a paisagem das terras da ex-usina, num processo histórico de reintegrações de posse e novas ocupações. Lima (2006, p. 73) explica que a materialização da ocupação de terra ocorre por meio dos acampamentos de reforma agrária, tendo como sentido sua dinâmica territorial provisória. Os sem terras, por meio de suas identidades socioculturais se organizam, e "da noite para o dia" "dominam, mesmo que temporariamente, uma parcela do território, pois o acampamento é, sem dúvida, uma forma espaço/tempo de enfrentamento do poder estabelecido".

Assim, em 2018, essas terras estão divididas entre 10 acampamentos, num total de 570 famílias agricultoras, que aguardam sua desapropriação oficial. Entretanto, um dos antigos acampamentos tornou-se o assentamento Nova Conquista II, a partir de 2014, onde estão instaladas 13 famílias, ocupando 300 hectares. No entanto sua situação difere do Primeiro do Sul, pois nele a monocultura da canade-açúcar deu lugar a centenas de lotes de plantação, cada qual com sua respectiva família posseira e diferentes culturas, o que significa que 3.600 hectares empregam aproximadamente 1.300 pessoas, 3,6 trabalhadores para cada 10 hectares, ou seja, um resultado empregatício $80 \%$ maior que o modelo de produção do agronegócio (DOTTA, 2017).

Em 2010 foi criado o Sindicado dos Agricultores Familiares de Campo do MeioMG, que congrega assentados do Primeiro do Sul, assentados e acampados da área da ex-usina, além de pequenos agricultores da região, e políticos que apoiam a luta pela terra. Além de ser "um órgão de representatividade de classe, um espaço de discussões políticas onde realiza-se o trabalho de conscientização política dos filiados, sobretudo os pequenos agricultores que estão tendo o primeiro contato com a luta pela terra" (LUCAS; VALE, 2014, p.20).

Outra alternativa encontrada por esses assentados e acampados para produzir fora do agronegócio foi a fundação da Cooperativa dos Camponeses Sul Mineiros (Camponesa), em 2012, da qual participam moradores dos assentamentos de Campo 
do Meio e de Guapé (Santo Dias), que tem como “objetivo social proporcionar melhor qualidade de vida e inclusão social aos camponeses sul mineiros, para o fortalecimento da solidariedade e da Agroecologia". Além do cultivo do café, da cana, do leite e seus derivados, os cooperados também produzem para autoconsumo, bem como a comercialização hortaliças, frutas (banana, melancia, maracujá, abacate, manga e goiaba), grãos (milho e feijão), e mel. Além disso, essas famílias também buscam ampliar suas rendas prestando serviços na colheita de café de outras propriedades rurais, além de receberem benefícios de políticas públicas como o Programa Bolsa Verde e Bolsa Família, do governo federal. A cooperativa organiza-se em vários grupos de produção: coletivos de mulheres, grupos do café, do grão, derivados da cana, pimenta, leite, polpas e frutas. Esses produtos são comercializados com a marca Guaií, em diversos eventos em nível nacional, e tendo como principal produto o café 6 .

\section{Produção agroecológica e reprodução social dos assentados Primeiro do Sul e Nova Conquista II}

A importância da adoção do sistema agroecológico nos assentamentos Primeiro do Sul e Nova Conquista II foi ressaltada por um dos membros do setor de produção do MST e da diretoria da cooperativa Camponesa ${ }^{7}$, entrevistado nesse trabalho.

O modelo agroecológico, além de trazer a soberania da família que está na terra, ela corta esse vínculo com o capital do agronegócio, capital que $100 \%$ das vezes escraviza o produtor. E o modelo agroecológico vai na contramão disso, desde a preservação do patrimônio genético com relação às sementes crioulas e práticas ambientais que vão recuperar as áreas que, na maioria das vezes nos assentamentos, são áreas já ocupadas com uma certa degradação que o monocultivo trouxe. Então, a agroecologia é uma saída para essa situação (Carvalho, 25 de maio de 2018).

Quando se fala em degradação ambiental, vê-se que essa também é uma preocupação nesses assentamentos e acampamentos. Em uma área coletiva no assentamento Nova Conquista II foi instalado um viveiro de mudas do MST, ligado ao projeto Recuperando Áreas Degradadas em Assentamentos de Reforma Agrária em Minas Gerais (RADAR), onde se pretende produzir 720 mil mudas, para serem plantadas ao redor de nascentes e áreas desmatadas (figura 2). "O projeto trabalha com o conceito de agrofloresta, que significa a conservação das matas (florestas)

\footnotetext{
${ }^{6}$ Maiores detalhes em http://www.guaii.com.br/quem-somos/cooperativa-camponesa.

${ }^{7}$ Ricardo Henrique de Carvalho é membro do setor de produção do Nova Conquista II, e é técnico agrícola formado pelo IFSULDEMINAS -Machado.
} 
e a produção de alimentos (agro) no mesmo território". Com isso, se espera que seja possível reflorestar cerca de 40 nascentes somente nas áreas do MST no Sul de Minas, tendo já sido procurado por outras organizações para a doação de mudas, inclusive por empresas do agronegócio (DOTTA, 2017, p. 2).

Figura 2: Viveiro de mudas no assentamento Nova Conquista II - Campo do Meio-MG.

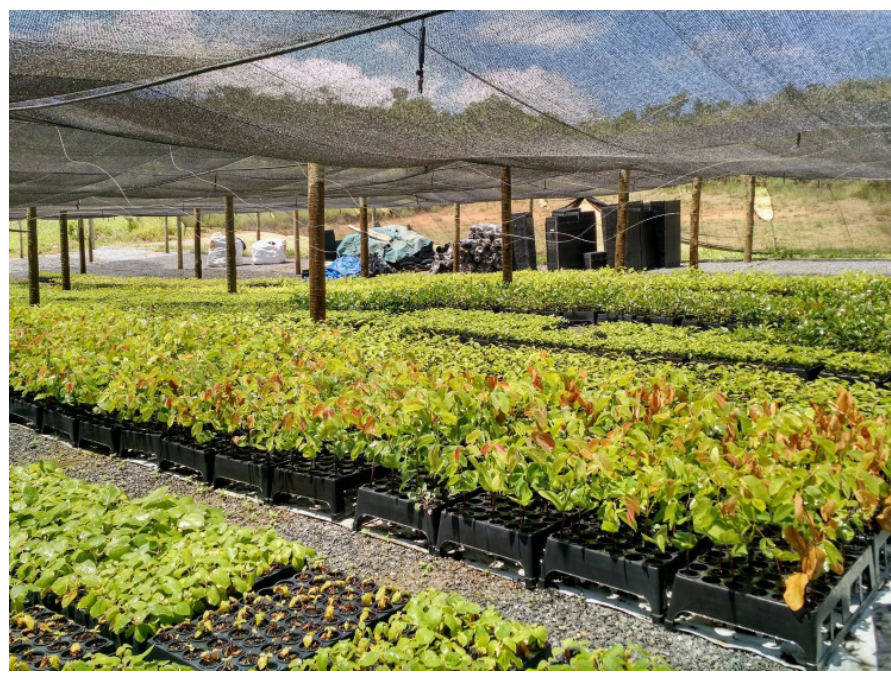

Fonte: Deivison Samuel Pereira de Alfenas, 01/02/2018.

Sobre os produtos agrícolas cultivados nos sistemas agroecológicos, além do café, há uma diversidade de produtos como banana, hortaliças, criação de animais e seus derivados, que são beneficiados para a venda. O entrevistado explica que agroecologia é sinônimo de diversidade. Portanto, embora o café seja o carro chefe da produção da cooperativa, ela é feita de uma forma diferenciada, porque ele é certificado, agroflorestal e, aliado a isso, os assentados estão fazendo práticas ambientais de preservação. No entanto, para que isso ocorra, é necessário um apoio técnico.

[...] o apoio técnico, geralmente, vem de militância, dentro do movimento (MST), de técnicos que vem. Hoje em dia a gente tem um ganho de formar os assentados em técnicos, em regime de alternância, capacitando então a juventude do campo, eu e os produtores também com esse curso, vamos trocar universidade e campo, num certo período, pra não se distanciar do campo também. Então, é importante essa didática diferente, de se estar passando para o pessoal do campo. Então, hoje o apoio técnico vem disso, 
de formar o próprio assentado, e da militância de todo um setor nacional do movimento, mas daí já entra na criação de cooperativas do movimento. As cooperativas já estão dando algum aporte, quando se tem um bom desenvolvimento, para poder estar tendo um apoio técnico, mas ainda é muito pouco. O apoio vem da militância mesmo (Carvalho, 25 de maio de 2018).

É importante ressaltar que a Pedagogia da Alternância à qual o entrevistado se referiu, "é um método que busca a interação entre o estudante que vive no campo e a realidade que ele vivencia em seu cotidiano, de forma a promover constante troca de conhecimentos entre seu ambiente de vida e o trabalho escolar ${ }^{8}$ ".

A respeito da organização da produção agroecológica nos assentamentos e acampamentos, Carvalho (2018) explicou que é um processo em desenvolvimento, já que a ruptura do manejo convencional para o agroecológico é complicada, devendo-se levar em conta em todo âmbito (histórico e cultural) dos assentados. Para o entrevistado, antes de romper esse laço é preciso estruturá-lo, e que "isso vai desde a reeducação do pessoal com essas práticas, para ter uma produção realmente agroecológica”.

Embora já existissem alguns assentados que não utilizavam insumos químicos em suas produções agrícolas, oficialmente, foi a partir de 2013, que as famílias do Primeiro do Sul iniciaram um projeto de transição do cultivo do café convencional para o orgânico, como forma de obter maior independência econômica, e obter um produto de melhor qualidade. Para 4 famílias que já vinham trabalhando com esse sistema de cultivo, a produção está sendo comercializada pela COOPFAM (Cooperativa dos Agricultores Familiares de Poço Fundo e Região), como um produto intitulado "Café Familiar da Terra", baseado no "sistema produtivo sustentável, com princípios e normas certificadas pelo Fair Trade e Cafeicultura Orgânica", buscando reforçar a agricultura familiar, e respeitar a natureza 9 .

Em entrevista para o site do MST, em 2013, sobre esse processo de transição na produção de café no Primeiro do Sul, um assentado, membro da diretoria da cooperativa Camponesa ${ }^{10}$, explicou a importância de se trabalhar no sistema de produção orgânico.

Para ter um produto de melhor qualidade, tanto para as famílias que trabalham quanto para os consumidores, pois o orgânico reflete a questão da saúde de todos. Além disso, os insumos industrializados comprometem muito o resultado da produção do agricultor. O produtor, na lógica de

\footnotetext{
${ }^{8} \mathrm{http}: / /$ portal.mec.gov.br/component/tags/tag/36222-pedagogia-da-alternancia ${ }^{9} \mathrm{http}: / /$ www.coopfam.com.br/.

${ }^{10}$ Roberto Carlos do Nascimento integra o MST do Sul de Minas desde 1998, no assentamento Primeiro do Sul e atualmente é assentado do Nova Conquista II.
} 
produção do café convencional, acaba trabalhando para a indústria e não tendo retorno nenhum. $\mathrm{O}$ cultivo de orgânicos possibilita a ele produzir a própria matéria-prima para atuar na adubação do café. Isso faz com que o capital dele gire em sua propriedade, sem depender da indústria externa (COUTINHO JÚNIOR, 2013, não paginado).

$\mathrm{Na}$ época, o entrevistado explicou com detalhes esse processo, que envolvem 21 famílias, por meio de um projeto financiado pelo CNPQ (Conselho Nacional de Desenvolvimento Científico e Tecnológico), com previsão de aproximadamente 2 anos de transição. Assim, puderam ter aulas práticas sobre o manejo agroecológico. "As famílias que participam do projeto vão ter um resultado que vai possibilitar a implantação desse cultivo em outras áreas. Acreditamos que dentro de três a quatro anos nós vamos ter pelo menos $50 \%$ das famílias produtoras já tendo uma área de seu lote com café orgânico". No entanto, também existem desafios a serem superados, como a degradação do solo anteriormente ocupado pela monocultura do café, e o acesso pelos assentados à própria matéria prima para suprir a necessidade nutricional da planta, pois eles ainda não têm condições de produzir insumos (COUTINHO JÚNIOR, 2013).

Sobre a cooperativa, o assentado ressaltou que no início houve resistência por parte dos assentados, por desconhecerem a proposta, mas que aos poucos começou a haver até disputa entre as famílias para filiação. Na verdade, explica que, como as famílias assentadas representam um grupo importante para as cooperativas de café convencional da região, fica difícil "implementar a discussão do MST da importância de trabalhar com uma produção alternativa, sem degradar o meio ambiente. Tanto para pautar este tema como para melhorar a situação econômica das famílias é que estamos organizando a nossa cooperativa" (COUTINHO JÚNIOR, 2013).

A questão de gênero também é contemplada dentro da Camponesa, uma vez que dela fazem parte o Coletivo de Mulheres Raízes da Terra, de Campo do Meio e Coletivo de Mulheres Olhos D'água, de Guapé, que congregam mais de 80 mulheres auto organizadas. "Esses coletivos são parte importante de nosso movimento e de nossa cooperativa, uma vez que produzem na perspectiva da agroecologia para a geração de renda, dignidade, e libertação ${ }^{11}$ ". Em entrevista ao site Brasil de Fato, uma das integrantes do Coletivo de Mulheres Raízes da Terra ${ }^{12}$ relata que o trabalho de produção é totalmente familiar e coletivo, tendo em vista que o cultivo de café exige muita mão de obra. Assim, muitas famílias trabalham em sistema de mutirão, principalmente durante a colheita, junto com os coletivos. Sobre o

\footnotetext{
${ }^{11} \mathrm{http}$ //www.guaii.com.br/quem-somos/coletivos-de-mulheres/.

${ }^{12}$ Tuira Tule Outono Ribeiro Péret Moraes faz parte da direção do setor de produção da regional do Sul de Minas Gerais.
} 
papel das mulheres nesse processo, ela explicou que "a relação da mulher com a produção de café tem outro tipo de ação. As mulheres estão envolvidas desde o plantio, nos tratos culturais, na colheita, e têm mulheres que produzem sozinhas essa cultura". Fazendo uma projeção para 2018, ela acredita que "a produção de café livre de agrotóxicos e transgênicos somarão 10 mil sacas, e mais famílias serão envolvidas no processo, que garante formação política e geração de renda" (GONÇALVES, 2018).

Quando questionado sobre as formas de escoamento da produção agroecológica dos assentamentos e acampamentos, Carvalho (2018) explicou que, no caso do café,

[...] já está sendo vendido para a cooperativa e as demais coisas, as hortaliças para as feiras. Então, hoje, uma conquista do movimento foi a criação dos armazéns: Armazéns do Campo em São Paulo, em Belo Horizonte, que dá esse escoamento de produção também, principalmente para os produtos que são minimamente processados, geleias, essas compotas de doces, pimentas, pra gente poder estar escoando (Carvalho, 25 de maio de 2018).

Os Armazéns do Campo, ao qual o entrevistado se refere, são lojas abastecidas principalmente com artigos produzidos nos assentamentos do MST em todo o país, incluindo alimentos orgânicos e não orgânicos, mas todos provenientes do modelo familiar de produção agrícola. Há também artigos de parceiros, também orgânicos e certificados, como açúcar, geleias, vinhos, carnes (de frango e bovina), cachaças e cafés, entre outros. Tais produtos são vendidos a preços mais acessíveis que nos supermercados, como forma de democratizar o acesso da população a uma nutrição mais saudável e sinalizando para a possibilidade de inverter a ordem atual da agricultura industrial, predominantemente ligada à monocultura (RABELLO, 2026).

As dificuldades com o escoamento da produção dos assentamentos são um ponto importante, destacado por Carvalho (2018):

Mas daí a gente já entra na questão da infraestrutura, que é complicado também. Então, assim, a gente ainda não tem agroindústria certificada, SIF (Serviço de Inspeção Federal), certificação de vigilância (sanitária), isso tudo que impedem a gente de estar levando esses produtos e essas altas taxações de produtos, que acabam inviabilizando também e a logística muito cara também, às vezes, fica caro levar um produto até Belo Horizonte, por exemplo, para escoar. E a nossa região aqui a gente está se estruturando (Carvalho, 25 de maio de 2018).

Regionalmente, os assentados e acampados vendem seus produtos agrícolas em 
feiras semanais, sendo que uma é na sede do próprio município, e outra é na Feira Agroecológica e Cultural de Alfenas (FACA), em Alfenas, criada com o apoio do projeto de extensão da UNIFAL-MG, denominado "Fórum de combate ao uso de agrotóxicos: soberania alimentar e agroecologia na região de Alfenas”, em 2017 (figuras 3 e 4).

Figuras 3 e 4 - Inauguração da Feira Agroecológica e Cultural de Alfenas (FACA), em Alfenas-MG (22/02/2017).
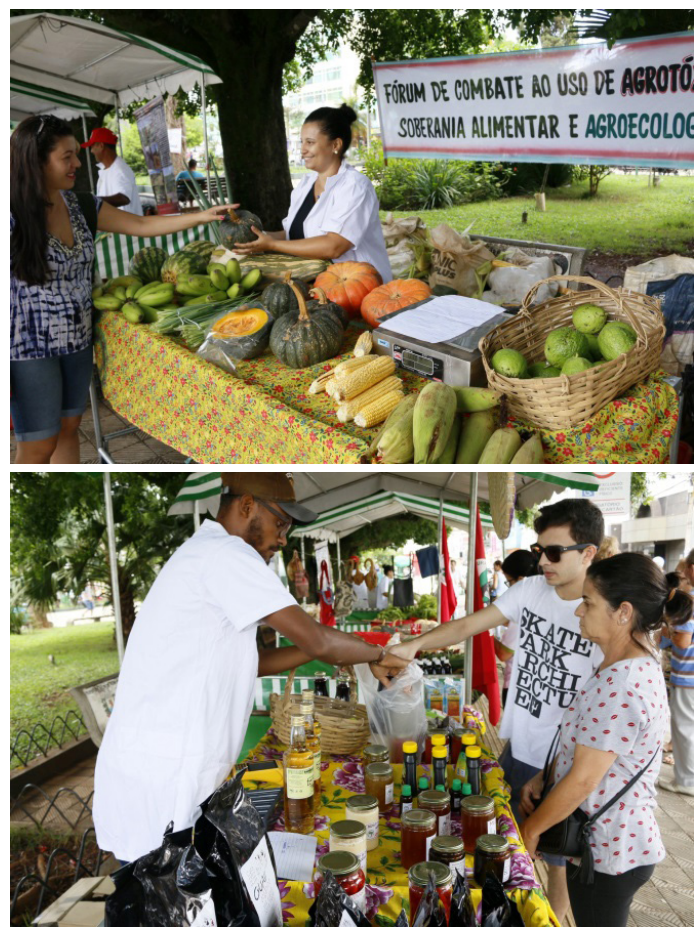

Fonte: Prefeitura Municipal de Alfenas (2017).

Além disso, Carvalho (2018) acrescenta que há também “os grupos de consumo também, que é para estar aumentando esse leque de escoamento mais perto para esses produtos mais in natura, que tem uma durabilidade menor", enquanto que "os processados a gente via estar levando para os outros armazéns: São Paulo, Belo Horizonte. Vão escoar por essas vias".

Apesar de tudo, para os assentados a cooperativa representa uma mudança, uma nova possibilidade de obtenção de renda, de forma coletiva, conforme explica o presidente da cooperativa. 
[...] é que com nossos cooperados a gente consegue, de certa forma, fazer com que eles participem do resultado da nossa cooperativa. A aquisição de insumos que a cooperativa consegue adquirir e repassa para os nossos cooperados para eles pagarem com prazo, sem acréscimo de juro, e o resultado da nossa produção a gente retorna para o cooperado uma parte do resultado do lucro. Então, essa é uma vantagem diferenciada dos outros tipos de cooperativa convencional que tem na própria região. E a participação, que temos reunião com frequência mensal, e é fundamental a participação deles. (Nascimento, 26 de maio de 2018).

No entanto, apenas essa estratégia é suficiente para manter a sobrevivência das famílias assentadas e acampadas no campo. Segundo Nascimento (2018), a cooperativa é uma "ferramenta importante na prova de resistência e avanço das famílias, dentro dos acampamentos e assentamentos”, mas não a única. É necessário um conjunto de ações. Eles esperam um crescimento dentro da linha da produção orgânica e agroecológica, que é o foco da Camponesa, ampliando o número de cooperados, que atualmente são de apenas 32 famílias, e a área cultivada "porque é uma questão de vida mesmo, é uma qualidade de vida mesmo, produzir orgânico e agroecológico". O entrevistado acredita que a agroecologia vai muito além da relação homem/natureza.

Ao trabalhar na forma agroecológica, a gente, além de cuidar do meio no qual a gente está inserido, a gente tem até uma forma diferente de lidar com o homem e a mulher. Tem que estar tudo interligado, porque não é só o fato da produção. A gente tem que estar... tem que ter todo envolvimento, desde a relação, a convivência, o jeito de lidar com o companheiro. Tem toda essa complexidade. Não é só o fato de produzir sem veneno, mas de entender que o homem também faz parte desse ambiente (Nascimento, 26 de maio de 2018).

\section{CONSIDERAÇões FINAIS}

A agricultura familiar, ao contrário do agronegócio, mostra-se como um modelo de produção diferenciado sobre a terra e os recursos naturais, principalmente, por compreender que deles depende sua sobrevivência. Por ser responsável pela produção da maior parte dos alimentos para a população brasileira, essas famílias têm respeito pela sua qualidade. Daí seu engajamento na agroecologia, que compreende o meio ambiente em seu todo, de uma forma mais ampla, aliando sociedade e natureza, com uma certa harmonia. Esse modelo de produção tem 
ganho cada vez mais espaço na agricultura brasileira, buscando um mercado que vem deixando de ser tão restrito, focado apenas na população de alta renda.

Nesse contexto surgem os assentados da reforma agrária que, a partir de uma ideologia que busca o caminho da justiça social, inclui a sustentabilidade (ecológica, social, econômica, política, cultural e ética). Nesses espaços o trabalho coletivo e solidário, em moldes agroecológicos, tem trazido bons resultados, permitindo que esses agricultores consigam romper com as amarras do agronegócio.

No caso dos assentamentos Primeiro do Sul e Nova Conquista II, oriundos de lutas pela terra, no município de Campo do Meio, esse processo vem caminhando de forma mais firme, no propósito de promover a soberania da família que está na terra e, sobretudo, permitir que a produção agroecológica seja reconhecida como uma estratégia de reprodução social. Mas será que isso está ocorrendo?

Embora alguns assentados do Primeiro do Sul, desde o início, não utilizassem produtos químicos em suas lavouras, até mesmo no café, o projeto agroecológico propriamente dito se inicia com a criação da Cooperativa Camponesa, tendo como principal produto o café. Além disso, contam também com outros produtos beneficiados como doces, geleias e molho de tomate, da marca Guaíi, além de produtos in natura, vendidos em feiras, na região e fora dela (Armazéns do Campo em Belo Horizonte e São Paulo). Nas feiras eles vêm tomando espaço, ganhando respeito, mesmo que a pequenos passos. Com suas embalagens simples, sem gastos com publicidade, e relativos baixos custos de distribuição, conseguem oferecer produtos de qualidade, sem acréscimo de valores abusivos (em relação aos produtos industrializados), o que resgata ou atrai novos consumidores. Também faz parte desse processo a produção de café orgânico de alguns assentados do Primeiro do Sul, comercializados com a COOPFAM, que compreende seus limites em termos de investimentos nos cafezais, e o viveiro de mudas para reflorestamento de nascentes e áreas degradadas.

Tudo isso é extremamente importante, mas diante de um Estado que privilegia o agronegócio, há muitos enfrentamentos pela frente, sobretudo com relação às dificuldades de escoamento da produção. As estradas que ligam as áreas dos assentamentos e acampamentos não têm condições muito favoráveis para deslocamentos diários, sem contar os custos com transporte e combustível. Também necessitam de uma infraestrutura para a instalação de uma agroindústria certificada, e todas as formas adequadas de colocar os produtos no mercado de uma forma legalizada. Portanto, a relação custo/benefício ainda é uma questão importante para os cooperados. No entanto, é perceptível a coragem e a vontade desses assentados em abraçar esse projeto, e não se deixar abater pelas dificuldades, afinal, integrantes 
de movimentos sociais como o MST, sabem que a luta é diária e que a vitória um dia chega, com a produção de alimentos saudáveis, e famílias podendo sobreviver com seu árduo trabalho da terra.

\section{REFERÊNCIAS}

ALTIERI, Miguel A. Agroecologia: a dinâmica produtiva da agricultura sustentável. Porto Alegre: Ed. Universidade/UFRGS, 1998. 95 p.

Agroecologia: bases científicas para uma agricultura sustentável. 3ed. São Paulo: Expressão Popular, AS-PTA, 2012.

CARVALHO, Ricardo Henrique. Entrevista concedida a AMARAL, Jéssica D. F. Campo do Meio (MG), 25 mai. 2018.

COALIZÃO DO CAFÉ et al.(Org.) Café: Vida, Produção e Trabalho - Agricultores Familiares e Assalariados Rurais. Florianópolis: Instituto Observatório Social, 2004. Disponível em: <www.observatoriosocial.org.br/download/cafe_maio2004BX. pdf. $>$ Acessado em: 25 mai. 2018.

COUTINHO JÚNIOR, José. Assentamento em Minas inicia transição do café convencional ao orgânico. MST, 29 de maio de 2013. <http://antigo.mst.org. br/Assentamento-em-Minas-Gerais-inicia-transicao-do-cafe-convencional-aoorganico>. Acessado em: 27 mai. 2018.

DOURADO, Nathan P. A agroecologia como estratégia de reprodução social da agricultura familiar camponesa e desenvolvimento rural sustentável no município de Poço Fundo-MG. 2017. 81f. Trabalho de Conclusão de Curso (Geografia Licenciatura), Universidade Federal de Alfenas, Alfenas, 2017.

EHLERS, E. Agricultura Sustentável: origens e perspectivas de um novo paradigma. São Paulo: Livros da Terra, 1996.

ESTEVAM, Douglas. Setor de Produção do MST e cooperativas. Diálogos, Propostas, Histórias para uma Cidadania Mundial. 03/2010. Disponível em: http://base.d-p-h.info/pt/fiches/dph/fiche-dph-8240.html. Acessado em: 10 jul. 2018. 
ENGELMANN, Solange. O papel da Reforma Agrária Popular no Brasil. MST. 26 set. 2016. Disponível em: http://www.mst.org.br/2016/09/26/o-papel-da-reformaagraria-popular-no-brasil.html. Acessado em 27 mai. 2018.

FERNANDES, B. M. Formação e Territorialização do MST no Brasil. In: MARAFON, G. J.; RUA, J.; RIBEIRO, M. A. (Org.) Abordagens teóricometodológicas em Geografia Agrária. Rio de Janeiro: EdUERJ, 2007, p.139-168.

FRANÇA, Caio Galvão; DEL GROSSI, Mauro Eduardo; MARQUES, Vicente P. M. de Azevedo. O censo agropecuário 2006 e a reforma agrária: aspectos metodológicos e primeiros resultados. Brasília: MDA, 2009. Disponível em:< nead. mda.gov.br/download.php?file.../debate/o_censo_2006_e_a_reforma_agraria.> Acessado em 25 mai. 2018.

. O censo agropecuário 2006 e a agricultura familiar no Brasil. Brasília: MDA, 2009. Disponível em: <http://repositorio.unb.br/bitstream/10482/14745/3/ LIVRO_CensoAgropecuario $\% 202006 \% 20 \mathrm{e} \% 20 \mathrm{a} \% 20$ agricultura $\% 20$ familiar. pdf.> Acessado em 25 mai. 2018.

GOMES, Elenice.; SILVEIRA, Paulo Roberto C. Agroecologia nos Assentamentos de Reforma Agrária - O Caso do Assentamento Alvorada/RS. In: CONGRESSO BRASILEIRO DE ECONOMIA E SOCIOLOGIA RURAL, 40, 2002, Passo Fundo. Anais... Passo Fundo: EDIUPF, 2002. Disponível em: <http://coral.ufsm. br/desenvolvimentorural/textos/44.pdf. $>$ Acesso em 9 jul. 2018.

GONÇALVES, Juliana. Café agroecológico Guaí transforma a vida de assentados no Sul de Minas Gerais. Brasil de Fato. São Paulo (SP), 23 fev. 2018. Disponível em: <https:/www.brasildefato.com.br/2018/02/23/cafe-agroecologico-guaiitransforma-a-vida-de-assentados-no-sul-de-minas-gerais/> Acessado em: 28 mai. 2018.

INSTITUTO BRASILEIRO DE GEOGRAFIA E ESTATÍSTICA. IBGE Cidades: Estado de Minas Gerais: Campo do Meio: Censo agropecuário, 2006. Disponível em: $<$ https://cidades.ibge.gov.br/xtras/temas.php?lang=\&codmun=311130\&idtem $\mathrm{a}=3$ \&search $=$ minas-gerais $\mid$ campo-do-meio|censo-agropecuario-2006 $>$. Acessado em: 25 de maio de 2018.

LAMARCHE, Hugues (Coord.) Agricultura familiar: uma realidade multiforme. 
Campinas: Editora da Unicamp, 1993.

LIMA, Eduardo C. Os movimentos sociais de luta pela terra e pela reforma agrária no Pontal do Paranapanema (SP): Dissidências e Dinâmica Territorial. 2006. 120 p. Tese (Doutorado em Geografia). Universidade Estadual Paulista. Instituto de Geociência e Ciências Exatas. Rio Claro, 2006. Disponível em: <http:// repositorio.unesp.br/handle/11449/96672.> Acessado em: 28 de maio de 2018.

LUCAS, Kelson S.; VALE, Ana Rute. Assentamento Primeiro do Sul: passado de luta, presente de resistência e futuro de incertezas. Geografia Ensino \& Pesquisa, v. 18, n. 1, p. 7-22, jan./abr. 2014.. Disponível em: <http://periodicos.ufsm.br/ geografia/article/view/7417>. Acessado em 25 mai. 2018.

MOREIRA, Aninha M. Estudo comparativo do uso da terra em unidades de produção familiar no nordeste paraense. 2008. 88p. Dissertação (Mestrado em Ciências Ambientais). Universidade Federal do Pará, Belém, 2008. Disponível em: <http://repositorio.ufpa.br/jspui/bitstream/2011/2860/1/Dissertacao_ EstudoComparativoUso.pdf.> Acessado em: 28 mai. 2018.

MOTA, Demes N. Tendências Produtivas da Cafeicultura (Coffea Arabica) no Assentamento Primeiro do Sul, Campo do Meio (MG): Abordagem Socioeconômica-ambiental. 2008. 72 p. Trabalho de Conclusão do Curso (Especialização em Agroecologia). Universidade Federal de Santa Catarina. Florianópolis, 2008. NASCIMENTO, Roberto Carlos. Entrevista concedida a AMARAL, Jéssica D. F. Campo do Meio (MG), 25 mai. 2018.

PLOEG, Jan Douwe Van der. Dez qualidades da agricultura familiar. Revista Agriculturas: experiências em agroecologia. Rio de Janeiro: AS-PTA, n 1, p. 7-14, fev. 2014. Disponível em: http://aspta.org.br/wp-content/uploads/2014/02/ Agriculturas_Caderno_Debate-N01_Baixa.pdf. Acesso em: 28 mai. 2018.

RABELLO, Tânia. MST abre loja de orgânicos. Os preços? Compensadores. Estadão. São Paulo. 26 ago. 2016. Alimentos Orgânicos. Disponível em:< http:// emais.estadao.com.br/blogs/alimentos-organicos/mst-abre-loja-de-organicos-osprecos-compensadores/>. Acessado em 26 mai. 2018.

RIBAS, Alexandre. MST: Reorganização político-territorial dos assentamentos e a consolidação do sistema cooperativista dos assentados. Revista NERA. Presidente Prudente, n. 1, p. 45-58, 1998. Disponível em: < https://bit.ly/2YJwtyB >. Acessado 
em 10 jul. 2018.

SHIMANSKI, Edina; SOUZA, Cimone Rozendo. A cooperação nos assentamentos do MST: superação da agricultura familiar? In: BRANDENDURG, Alfio; FERREIRA, Ângela Duarte D. (org.) Ruralidades e questões ambientais: estudo sobre estratégias, projetose políticas. Brasília: MDA, 2007, p. 243-272. Disponível em: <http://www.reformaagrariaemdados.org.br/sites/default/files/jornl.pdf.> Acessado em 12 jul. 2018.

VEIGA, José E. Agricultura familiar e sustentabilidade. Cadernos de Ciência \& Tecnologia, Brasília, n.3, p.383-404, 1996. Disponível em: <https://seer.sct. embrapa.br/index.php/cct/article/view/9009/5115>. Acessado em 26 mai. 2018. 